\title{
Os desafios da avaliação no campo da Saúde Mental
}

\author{
Luciane Prado Kantorski ${ }^{1}$
}

A avaliação de experiências inovadoras de composição de redes de atenção psicossocial, delimitadas no contexto das políticas de reforma psiquiátrica e das práticas de reabilitação psicossocial, pressupõe uma contextualização destas práticas.

Nas últimas décadas, a incorporação progressiva dos princípios da reforma psiquiátrica foi materializada no contexto brasileiro pelas portarias do Ministério da Saúde - 189/1991 e 224/1992 - e pela criação dos novos serviços. Essa regulamentação permitiu: que passassem a ser remunerados novos procedimentos como consulta individual e em grupo por profissionais como enfermeiros, psicólogos e assistentes sociais; atendimento em oficinas terapêuticas, centros de atenção psicossocial, hospital-dia, urgência e internação em hospital geral; a definição de padrões mínimos para o funcionamento dos serviços de saúde mental com vistas à construção de uma rede diversificada de assistência. Em 19 de fevereiro de 2002 a portaria 336/2002 classifica em ordem crescente por abrangência populacional e por complexidade os Centros de Atenção Psicossocial, definindo a equipe mínima de profissionais e estabelecendo sua clientela-alvo ${ }^{(1)}$.

Atualmente, temos mais de 1.600 Centros de Atenção Psicosocial (CAPS) implantados no Brasil. Uma questão que merece ser considerada é de que os CAPS surgem como serviços estratégicos no interior de uma rede de atenção psicossocial. Esta mudança exige a implantação de uma diversidade de serviços de saúde que respondam aos diferentes momentos e necessidades da pessoa.

A consolidação da reforma psiquiátrica brasileira implica em transformar saberes e práticas em relação à loucura, perceber a complexidade do objeto de intervenção, recompreender o sofrimento psíquico, e efetivamente destruir manicômios externos e internos que têm permitido a constituição de determinadas formas de pensar e agir e, fundamentalmente, reinventar modos de se lidar com a realidade.

As diretrizes centrais da Política de Saúde Mental no Brasil, apontada pelo Ministério da Saúde e orientada pela perspectiva de reforma psiquiátrica, consistem, entre outros aspectos, na redução progressiva e gradual dos leitos em hospitais psiquiátricos, na garantia de assistência aos pacientes egressos dos hospitais, na criação e sustentação da rede extra-hospitalar - CAPS, residências terapêuticas, centros de convivência, ambulatórios, programas de suporte social, defesa e promoção dos direitos humanos dos pacientes e familiares.

Neste cenário a pesquisa em Saúde Mental pode contribuir com o acúmulo acadêmico e apoio das agências de financiamento para avaliar a estrutura, o processo e acrescentar nos resultados desta política de saúde mental. Avaliar redes reabilitadoras pressupõe a composição de um desenho teórico-metodológico esboçado que tenha como um dos interlocutores estratégicos os CAPS.

De 2005 a 2008 nos dedicamos a elaborar, executar e iniciar a divulgação de uma pesquisa contemplada pelo Edital MCT-CNPq/CT-Saúde/MS-SCTIE-DECIT 07/2005, que avaliou Centros de Atenção Psicossocial da Região Sul (Rio Grande do Sul, Santa Catarina, Paraná) do Brasil. Investigamos aspectos de estrutura, processo de trabalho e resultados dos CAPS, ouvindo usuários, familiares, trabalhadores e coordenadores dos serviços nos três estados, a partir de uma pesquisa que se desdobrou em um estudo qualitativo e um estudo quantitativo.

No Estudo de Avaliação Quantitativa do CAPS - abordagem epidemiológica avaliou a estrutura (por meio de questionários autoaplicados a 30 coordenadores dos CAPS), o processo (a partir de questionários autoaplicados a 435 trabalhadores desses CAPS) e o resultado da atenção em saúde mental (aplicando um questionário a 1.162 usuários, seguido da auditoria de registro do respectivo prontuário, e a 936 familiares dos 30 CAPS). O Estudo de Avaliação Qualitativa do CAPS foi desenvolvido a partir da avaliação construtivista, responsiva e com abordagem hermenêuticodialética, a Avaliação de Quarta Geração, em que foram feito cinco estudos de caso por meio de entrevistas com 
equipe, usuários e familiares dos CAPS (definidos como grupos de interesse para compor o círculo hermenêuticodialético) e observação de campo (entre 282 e 650 horas configurando-se numa etnografia prévia).

A avaliação de serviços de atenção psicossocial implica em reconhecer as portas que se abrem nas modalidades de atenção comunitária, o modo como elas tensionam os estigmas, os preconceitos e os rótulos dos serviços que se propõem a romper com a lógica da institucionalização e da exclusão.

A experiência em realizar esta pesquisa também nos apontou caminhos que sugerem avaliar pontos nevrálgicos da reforma psiquiátrica e fazê-lo a partir de cenários específicos, ou seja, a partir de experiências inovadoras que pretendem romper com a lógica manicomial.

Consideramos que uma avaliação que pretenda atingir pontos nevrálgicos no interior desta rede de atenção psicossocial precisa focalizar os grupos que se beneficiam ou que podem se constituir vítimas do processo avaliativo (2). A avaliação necessita incluir a escuta dos sujeitos vulneráveis às vicissitudes decorrentes de longos anos de institucionalização psiquiátrica, aqueles para os quais o conceito de cuidado, de tratamento precisa ser redimensionado. Também precisa considerar a perspectiva daqueles que desfrutam do sabor amargo de todo tipo de vulnerabilidade social, afetiva, financeira.

A possibilidade de se tratar, morar e viver no território, a partir da criação desses equipamentos exige a construção de espaços concretos de troca e sociabilidade, com vistas à inserção social. A avaliação de inovações constituídas no processo de atenção psicossocial, a partir do mapeamento das redes do cotidiano dos usuários de serviços de saúde mental é uma das formas de identificar potencialidades e limites nesta construção.

A enfermagem tem muito a contribuir com a construção da reforma psiquiátrica no país e no processo de avaliação dos serviços e da política de saúde mental. Mas é necessário percebermos que as opções que fazemos podem favorecer a conformação de saberes e práticas manicomiais ou a sua transformação. Como sujeitos deste processo, somos chamados a protagonizar mudanças no ensino, na pesquisa e na assistência que podem redimensionar a vida das pessoas e os sentidos do nosso fazer. Deste modo é fundamental assumir que um dos sentidos imperativos das práticas de enfermagem é cuidar de pessoas, resistindo a tudo que aprisiona o viver, a expressão da fala, a subjetividade das pessoas que desejamos cuidar.

\section{REFERÊNCIAS}

1. Secretária Executiva, Ministério da Saúde. Legislação em saúde mental: 1990-2004 [Internet]. 5th ed. ampliada. Brasília: Ministério da Saúde, 2004 [cited 2012 mar 29]. Available from: http://bvsms.saude.gov.br/bvs/publicacoes/legislacao mental.pdf.

2. Guba E, Lincoln Y. Fourth Generation Evaluation. Newbury Park: Sage Publications, 1989.

${ }_{1}^{1}$ Enfermeira, Doutora em Enfermagem, Professora Associada, Faculdade de Enfermagem, Universidade Federal de Pelotas. Pelotas, RS, Brasil. E-mail: kantorski@uol.com.br. 